\title{
DEVELOPMENT OF THRESHOLDS FOR INSECTICIDAL CONTROL OF NEW ZEALAND FLOWER THRIPS ON NECTARINES IN SPRING
}

\author{
G.F. McLAREN and J.A. FRASER
}

\author{
The Horticulture and Food Research Institute of New Zealand Ltd., \\ Clyde Research Centre, R.D. 1 Alexandra, Central Otago
}

\begin{abstract}
Numbers of adult and larval New Zealand flower thrips, Thrips obscuratus, were recorded daily on nectarines from flowering (early September) to shuck fall (early November) over 5 years. Adults were more common than larvae and occurred throughout this period, increasing to their highest numbers in late October. Larvae occurred for three weeks from petal fall. Adults were released weekly onto bagged nectarine flowers or fruitlets, from flowering to shuck fall. Damage to the fruit was assessed in November. Adults caused the most severe damage when released during flowering; slightly less damage was caused after petal fall and minor damage occurred in the weeks before shuck fall. Adult feeding did not affect fruit set. Three thresholds based on adult numbers are proposed for determining the need for insecticidal control in an Integrated Fruit Production programme for nectarines. These thresholds reflect the decreasing risk of damage through the sensitive period.
\end{abstract}

Keywords: thrips, nectarines, damage, spray threshold, integrated fruit production.

\section{INTRODUCTION}

Flower thrips cause russet damage to nectarines (Prunus persica (L.) Batsch var. nucipersica (Suckow) C.K. Schneid) in many countries. The most common species responsible is the western flower thrips Frankliniella occidentalis (Pergande) (Bailey 1938; Felland et al. 1995; La Rue et al. 1972; Yonce et al. 1990) but other species also cause damage (Jacobs 1995; Kourmadas et al. 1982). There are anecdotal reports of thrips reducing yields, although there appears to be no published evidence for this. In the case of western flower thrips, the larvae that appear after petal fall are reported to be responsible for most of the damage and are most effectively controlled by applying an insecticide over flowering (Black et al. 1963; Jacobs 1995).

In New Zealand, adults of the endemic New Zealand flower thrips (NZFT), Thrips obscuratus Crawford, have been associated with damage to nectarines in the spring (McLaren 1992). Russet damage on the fruit at harvest time $\left(>0.75 \mathrm{~cm}^{2}\right.$ or $>1 \mathrm{~cm}$ long) can cause its rejection from the export line.

Adult thrips fly into nectarine orchards as they start to flower in early to midSeptember and feed on nectar and pollen. They lay their eggs in the outer calyx of the flower. When the fruit starts to grow the calyx protects the fruit until it splits ("burst calyx') in late October, then withers and is shed ('shuck fall') in early November. Adult thrips shelter inside the calyx until the fruit has emerged fully and the old flower parts have been shed. They then leave the fruit. The eggs hatch and larvae appear from the end of flowering to mid October. Pupation takes place on the ground.

Monitoring methods and "spray thresholds" are needed for the period from flowering to shuck fall, to assist growers using the new Integrated Fruit Production programme for summerfruit (Summergreen ${ }^{\mathrm{TM}}$ ) to decide on their need to apply insecticides. This paper describes the identification of key times and thresholds for spraying. 


\section{Tree sampling}

\section{METHODS}

Sampling was carried out daily from 9 September (beginning of flowering) to 5 November (shuck fall) each year from 1995 to 1999 on insecticide-free trees (planted in 1992) of nectarine cv. Fantasia growing at Clyde Research Centre, Central Otago. Ten trees were sampled each day between 1000 and 1200 hours with the same trees being resampled every ten days. Sampling was conducted by tapping most of the branches of each tree within reach from the ground using a $150 \mathrm{~mm}$ length of galvanized pipe and holding a $250 \mathrm{~mm}$ yellow plastic plate under the branch (G.F. McLaren, unpubl. data). The number of taps per tree was limited to 20 . The numbers of thrips caught, their stage and species were recorded. Thrips damage on 80 randomly selected fruit from neighbouring unsprayed blocks was assessed at harvest time each year. Fruit were recorded as undamaged (Grade 0), damaged but within export grade standards (Grade 1), not acceptable for export (Grade 2) or unsaleable (Grade 3). The observed damage at harvest over five years was compared with numbers of NZFT adults and larvae in spring by regression analysis. Percentage export grade was related to thrips numbers over three different periods: flowering (9 September to $90 \%$ petal fall - 21 days approximately), 9 September to 15 October (37 days) and 9 September to 5 November (57 days).

\section{Bagging Experiments}

In 1995 and 1996, 100 nectarine twigs (100-150 mm long) carrying closed flower buds were selected at random on 20 trees in a block of 50 trees at Clyde Research Centre. The twigs were covered with cotton bags $(200 \times 150 \mathrm{~mm})$ which were secured at the base with a wire twist. Each week, ten bags were removed and ten adult NZFT (collected from flowers of either gorse Ulex europaeus L. or cherry Prunus avium L.) were released inside each bag; the bags were then placed back on the same twig. Releases were made over eight weeks from early bloom (mid September) to shuck fall (early November). One set of ten twigs was never infested; another set was never bagged. The bags were removed for the first and last time on either 8 November 1995 or 26 November 1996, and the percentage surface area of the fruit damaged by thrips was estimated. No insecticides were applied to the trial plots throughout these experiments, but fungicides were applied to the whole block over flowering.

In 1999, 80 twigs were thinned to four tightly closed flower buds on 14 September and bagged (as above). In order to kill any thrips that may have been infested the buds, the bags had been dipped in a short-term insecticide pyrethrum and dried before installation. Ten thrips were released into each of eight bags each week from 15 September. Seven days after thrips introduction, the bags were removed, both the twig and the bag were shaken over a plate, and the numbers of live and dead thrips recorded. To ensure no live thrips returned, the insides of the bags were sprayed with a commercial aerosol spray containing permethrin, tetramethrin and piperonyl butoxide before they were placed back on the twig. One set of twigs was never infested and one set was never covered. Each fruit was graded into one of four grades on 23 November 1999: $0=$ no damage, $1=$ minor damage, $2=$ damaged and $3=$ severely damaged. Grades 0 and 1 were both expected to meet export standards.

Fruit damage and thrips survival were analysed in relation to the time of thrips release using analysis of variance in S-Plus (MathSoft 1999). Estimates of fruit damage from the bagging experiments in 1995 and 1996 were calculated as the weighted percentage area damaged, and in 1999 the weighted damage score (weighting adjusted for the different number of fruit in each bag). In 1999, fruit set and thrips survival after one week were determined and the relationships between the number of live thrips recovered each week and fruit set and fruit grade were investigated.

\section{Tree Sampling}

\section{RESULTS}

Adult NZFT were found on nectarine trees from approximately $10 \%$ bloom to shuck fall, a period of eight weeks. Adult numbers were generally low over flowering and did not increase until late October when the second generation of adults emerged. Results are presented for spring 1998 and 1999 only (Fig. 1) but the pattern of low 

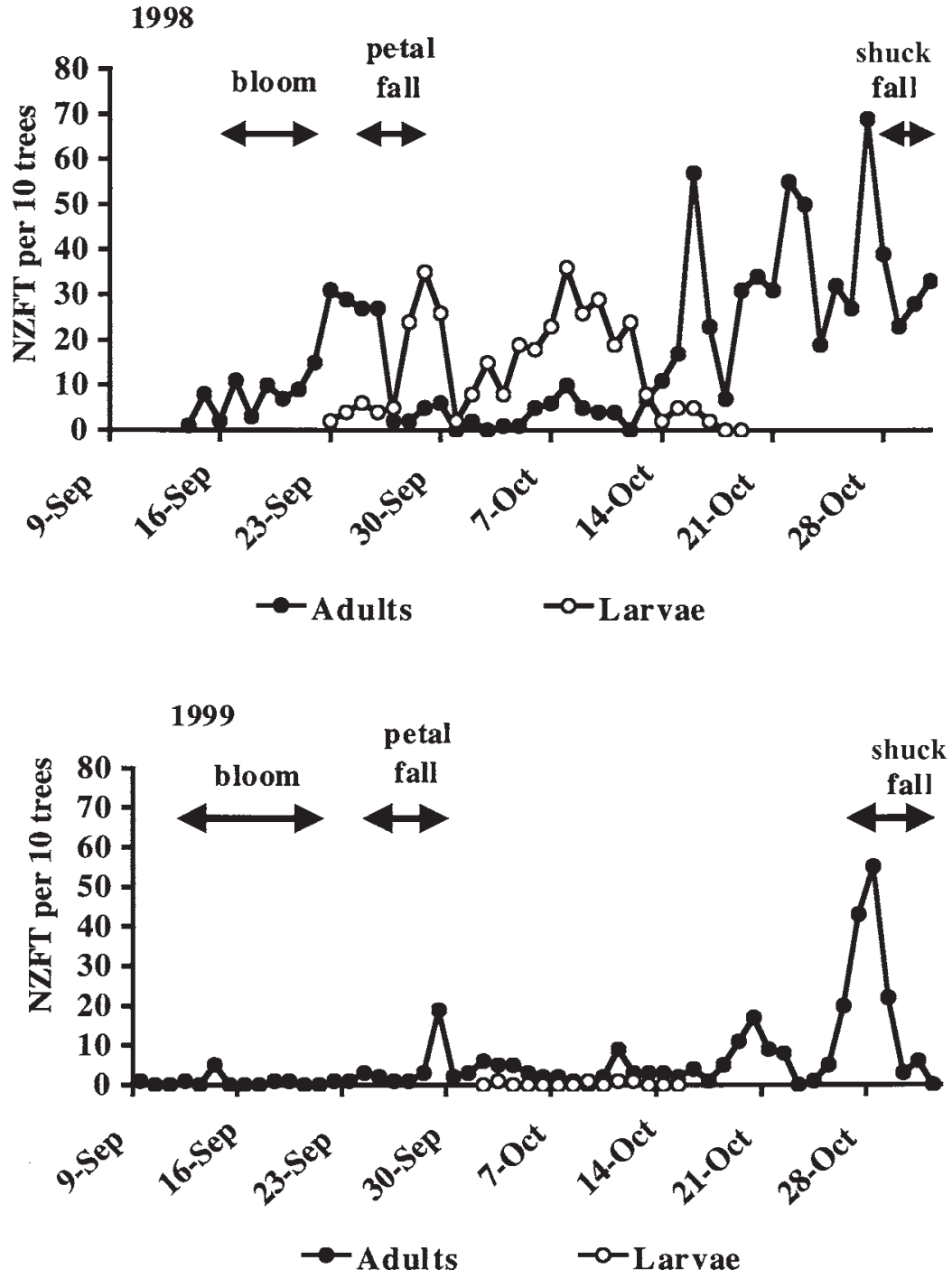

FIGURE 1: Numbers of $T$. obscuratus adults and larvae collected from ten unsprayed nectarine trees between flowering and shuck fall in 1998 and 1999.

numbers over flowering was similar each year. The highest numbers of both adults and larvae in the five years occurred in 1996 and this was the year with the most damage (lowest export packout) and highest adult numbers over flowering (Table 1). In 1998, larval numbers were relatively high and represented $26 \%$ of the population, but the level of damage to unsprayed fruit in adjacent blocks was low. In contrast, larvae represented just 1-2\% of the population in 1997 and 1999, yet thrips damage still occurred. Total adult and larval numbers for the period 9 September -5 November 
were both negatively correlated with percentage export grade over the five years. The correlation between adult numbers and percentage export grade was better for adults $(\mathrm{P}<0.001)$ than that for the larvae $(\mathrm{P}<0.05)$. The correlation between percentage export grade and adult numbers from 9 September to $90 \%$ petal fall was not significant $(\mathrm{P}>0.05)$ but the period 9 September to 15 October was significant $(\mathrm{P}<0.05)$.

TABLE 1: Time of emergence of NZFT larvae on unsprayed nectarines, total number of adults and larvae recorded from daily sampling on $\mathbf{1 0}$ trees and percentage export fruit at harvest time.

\begin{tabular}{llcccc}
\hline Year & $\begin{array}{c}\text { Date of first record } \\
\text { of larvae } \\
\text { (and 90\% petal fall) }\end{array}$ & $\begin{array}{c}\text { Adults } \\
\text { 9 Sept }- \\
\text { 15 Oct }\end{array}$ & $\begin{array}{c}\text { Adults } \\
\text { 9 Sept }- \\
\text { 5 Nov }\end{array}$ & $\begin{array}{c}\text { Larvae } \\
\text { 9 Sept }- \\
\text { 5 Nov }\end{array}$ & $\begin{array}{c}\text { \% export } \\
\text { grade at } \\
\text { harvest }^{1}\end{array}$ \\
\hline 1995 & 5 October (9 Oct.) & 191 & 1006 & 153 & 58 \\
1996 & 28 September (29 Sept.) & 494 & 3381 & 827 & 21 \\
1997 & 11 October (5 Oct.) & 30 & 693 & 14 & 79 \\
1998 & 23 September (26 Sept.) & 239 & 1014 & 355 & 54 \\
1999 & 3 October (25 Sept.) & 91 & 627 & 4 & 55 \\
Correlation with \% export & $\mathrm{R}^{2}$ & -0.89 & -0.99 & -0.80 & \\
& $\mathrm{P}$ & $<0.05$ & $<0.001$ & $<0.05$ & \\
\hline
\end{tabular}

${ }^{1}$ Fruit graded for thrips damage only.

\section{Bagging Experiments}

In 1995, on average $45 \%$ of the area of each fruit was damaged when thrips were released prior to petal fall (Fig. 2). The average excludes the result for 27 September 1995 when there was minimal damage, probably due to the toxicity of ziram residues, which had been applied to the whole block the day before the thrips were released. It is now known that ziram is toxic to NZFT (G.F. McLaren, unpubl. data) and this product was not used again in the experimental area. The expression of fruit damage in 1996 was generally less than that in 1995. Nevertheless, in both years, the damage to fruit exposed to thrips prior to petal fall was greater than that to fruit exposed after petal fall $(\mathrm{P}<0.05$ in $1995 ; \mathrm{P}<0.001$ in 1996).

In 1999, the flowers on each tagged twig were thinned to 4 flower buds. Inside the bags, an average of 1.1 fruit set/four buds, which was less than the 2.0 fruit/four buds that set in the open $(\mathrm{P}<0.01)$. Fruit set was not related to the number of thrips surviving in the bag after 1 week $(\mathrm{P}>0.05)$ nor the timing of their introduction $(\mathrm{P}>0.05)$, indicating that adult thrips do not influence fruit set. Thrips introduction over flowering (weeks $1-3$ ) resulted in the greatest level of damage (Fig. 3). Damage was less when thrips were introduced at $100 \%$ petal fall (week 4), increased briefly (week 5) before declining to negligible levels (close to the bagged control) by week 8 in early November.

\section{DISCUSSION}

Adults did not survive for long inside the bags. In 1995, no live adults were found from the first 5 weeks of releases but 16 adults (all released in the previous three weeks) and 10 larvae were observed when the bags were opened on 8 November 1995 (640 adults had been released). However, to better define the period when damage could be caused, the trial in 1999 aimed to kill any thrips already present on the buds before bagging and to kill released thrips after they had been in the bags for seven days. Treatment of the bags with pyrethrum two days before the first thrips were released on 15 September 1999 may have been responsible for the particularly low survival of adults in week 1 compared with week 2 (Fig. 3).

There was no evidence that NZFT affected fruit set. The difference between fruit set inside and outside the bags is likely to be explained by the exclusion of bees from the bagged flowers.

Larvae probably do cause damage to developing fruit but their contribution to overall damage appears to be low. This is partly because they do not appear until after 


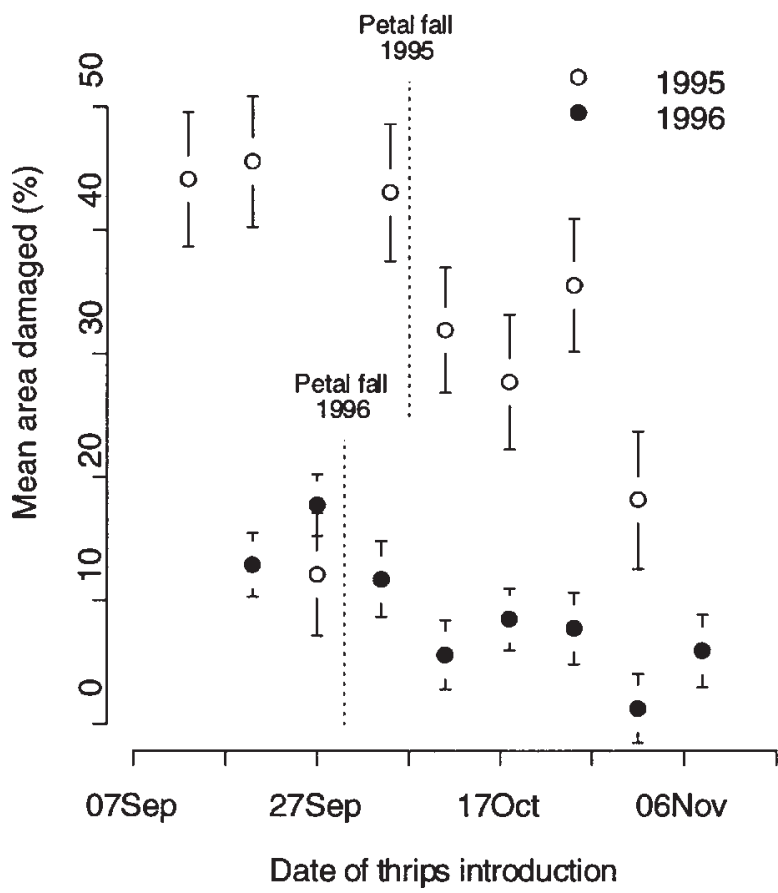

FIGURE 2: Nectarine damage (\% surface area) assessed in November 1995 and 1996 following weekly releases of adult T. obscuratus. Standard errors are presented as error bars.

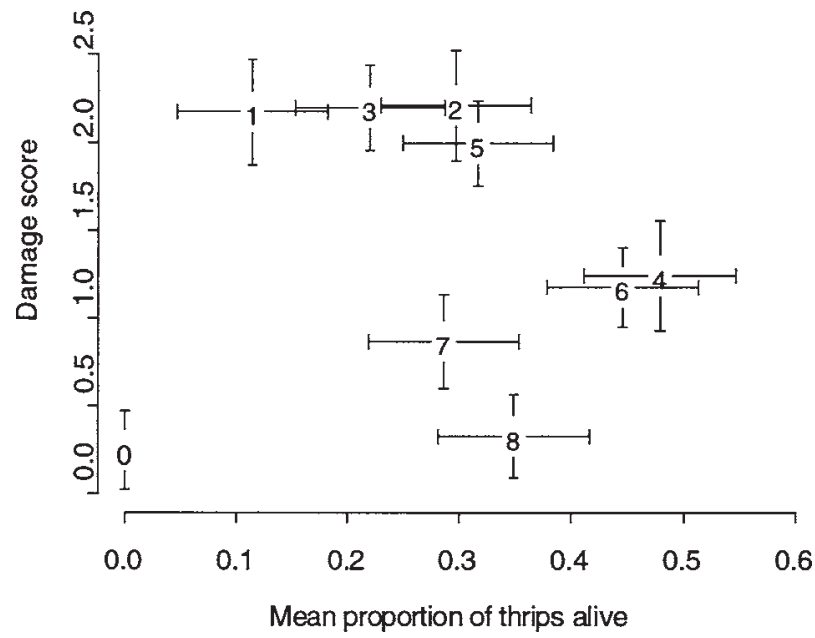

FIGURE 3: Severity of damage to nectarines in relation to survival of T. obscuratus after one week on nectarine fruitlets over eight weeks $(1-8)$ in 1999. Standard errors for both parameters are presented as error bars for each data point. 
petal fall and even then are less common than the adults, but more importantly, because damage still occurred in years when larval numbers were extremely low. Furthermore, larval numbers did not correlate as well with damage as adult numbers. The relative efficiency of sampling for larvae compared with adults has not been determined but since the importance of adults has been established, monitoring methods for NZFT have been developed based on that stage.

Tree sampling showed that adults are present in low numbers over the flowering period and remain low for 7-10 days after $90 \%$ petal fall. Their numbers increase to a maximum in late October, as the second generation emerges. In contrast, both the bagging experiments and the correlation between adult numbers and fruit damage demonstrated that the fruitlets were more susceptible to damage at flowering than they were in late October. Therefore although adult NZFT occur in low numbers over bloom, they are associated with greater damage then than those occurring between $90 \%$ petal fall and shuck fall.

\section{Spray Thresholds}

The information from these experiments on the changes in the sensitivity of the fruit to thrips feeding between flowering and shuck fall has been considered when developing preliminary "spray thresholds" for use in the Integrated Fruit Production programme (Summergreen ${ }^{\mathrm{TM}}$ ) introduced in 1999. Growers use the same sampling technique to monitor their trees as has been described here but sample only once per week using 20 taps/ tree on 10 trees (or 20 small trees). The thrips-sensitive period has been divided into three, the first two representing the 9 September -15 October period in Table 1. Preliminary thresholds have been set at:

\section{Tree stage}

- $5 \%$ bloom to $90 \%$ petal fall

- $90 \%$ petal fall to two weeks later

- two weeks after petal fall to shuck fall

\section{Spray Thresholds}

5 or more thrips/10 trees

10 or more thrips/10 trees

50 or more thrips/10 trees

These thresholds combine the present experimental information with information gathered from sampling 28 blocks of nectarines every week over five seasons 19791984 using the same tree sampling method.

\section{ACKNOWLEDGEMENTS}

We thank Peter Alspach, HortResearch, Riwaka Research Centre for the statistical analyses. This work was funded by the New Zealand Foundation for Research, Science and Technology, Contract number CO6615.

\section{REFERENCES}

Bailey, S.F., 1938. Thrips of economic importance in California. Univ. Calif. Agric. Expt. Stn. Circ. 346.

Black, J.H., Davis,C.S., Burton, V.E. and Hench, K.W., 1963. Thrips control on nectarines. California Agriculture 17(3): 6-7.

Felland, C.M., Teulon, D.A.J., Hull, L.A. and Polk, D.F., 1995. Distribution and management of thrips (Thysanoptera: Thripidae) on nectarine in the mid-Atlantic region. J. Econ. Entomol. 88(4): 1004-1011.

Jacobs, S., 1995. Thrips damage and control in nectarine orchards. Deciduous Fruit Grower 45(7): 274-280.

Kourmadas, A.L., Zestas, T. and Argriou, L.C., 1982. Timing of spraying for control of thrips in nectarine trees. Annals Inst. Phytopath. Benaki (N.S.) 13: 120-129.

LaRue, J.H., Dibble, J.E. and Obenauf, G., 1972. Thrips in nectarines; their injury and recent control investigations. The Blue Anchor, Spring: 22-25.

MathSoft 1999. S-Plus 2000 Guide to Statistics, Volume 1. Data Analysis products Division, MathSoft, Seattle, WA.

McLaren, G.F., 1992. Thrips on nectarines in the spring. Proc. 45th N. Z. Plant Prot. Conf: : 111-115.

Yonce, C.E., Beshear, R.J., Payne, J.A. and Horton, D.L., 1990. Population distribution of flower thrips and the western flower thrips (Thysanoptera: Thripidae) in nectarines and their relative association with injury to fruit in the southeastern United States. J. Entomol. Sci. 25(3): 427-438. 